\title{
Prevalence of Early Removal of Long-Acting Contraceptive Methods and Its Associated Factors in Sidama Regional State, Ethiopia
}

This article was published in the following Dove Press journal: Open Access Journal of Contraception

\author{
Ephrem Geja (iD) \\ Fanuel Belayneh (iD ${ }^{2}$ \\ Deresse Legesse ${ }^{2}$ \\ Desalegn Tsegaw (iD ${ }^{2}$ \\ Teshome Abuka² \\ Addis Gebremariam ${ }^{3}$ \\ Henok Gebreyohaness ${ }^{4}$ \\ Dawit Jember (iD) ${ }^{2}$ \\ Zewdie Oltaye ID $^{\prime}$ \\ Alelign Tadele ${ }^{5}$ \\ 'School of Nursing, College of Medicine \\ and Health Sciences, Hawassa University, \\ Hawassa, Sidama Regional State, Ethiopia; \\ ${ }^{2}$ School of Public Health, College of \\ Medicine and Health Sciences, Hawassa \\ University, Hawassa, Sidama Regional \\ State, Ethiopia; ${ }^{3}$ Hawassa University \\ Comprehensive Specialized Hospital, \\ Hawassa, Sidama Regional State, Ethiopia; \\ ${ }^{4}$ Yale Global Health Leadership Institute, \\ Yale School of Public Health, Gondar, \\ Ethiopia; ${ }^{5}$ Department of Medical \\ Laboratory Science, Hawassa Health \\ Sciences College, Hawassa, Sidama \\ Regional State, Ethiopia
}

Background: Long-acting reversible contraceptive methods, IUD and sub-dermal implant, offer women the most effective method to control fertility. Yet, reports on high early removal rates were emerged, prompting concern among service providers and highlighting the need to review removal rates and its reasons. Therefore, this study was conducted to assess the prevalence of early removal rates of LARCs and its associated factors in Sidama Regional State, Southern Ethiopia.

Methods: Community-based cross-sectional study was conducted in Sidama Regional State, Ethiopia from June 1 to June 30, 2019. A multistage sampling technique was used to select 21 administrative units in the first stage. Then, systematic sampling was used to select 475 women who have ever used implants or IUD 3 years preceding the data collection period. Data were entered into Epi Info version 3.4.3 and exported to SPSS version 20 for analysis. Descriptive statistics, bivariate, and multivariate logistic regression were computed. P-value $<0.05$ was used to declare a significant association.

Results: The mean $( \pm \mathrm{SD})$ of the participant's age was $29.81( \pm 5.69)$ years. The prevalence of early removal rate of LARCs was $10.3 \%$, ie, 43 (10.8\%) among Implanon/jadelle users and $6(7.8 \%)$ among IUD users. Eleven $(22.4 \%)$ discontinued within the first six months and $38(77.6 \%)$ utilized for more than six months and discontinued before the 12th month. Women who were not advised about advantage $[\mathrm{OR}=2.81$ (95\% CI: $1.23-6.40)]$ and effectiveness of contraceptive $[\mathrm{OR}=2.70(95 \% \mathrm{CI}: 1.30-5.60)]$ and those who were satisfied with the family planning service $[\mathrm{OR}=2.24(95 \% \mathrm{CI}: 1.10-4.57)]$ were identified as factors. Conclusions: The prevalence of early removal rate was considerably high among the study subjects. Providing appropriate counseling about the advantage and effectiveness of family planning and improving client satisfaction need to be considered to reduce the early removal rate.

Keywords: IUD, Implanon, jadelle

\section{Introduction}

Long-Acting Reversible Contraceptive (LARC) devices which include the IntraUterine copper Contraceptive (IUD) and the etonogestrel contraceptive implant are among currently available long-acting contraceptive options in Ethiopia. These methods are classified as long-acting methods due to long-term contraceptive efficacy. ${ }^{1}$ Intra-Uterine Devices (IUDs) are T-shaped devices that must be inserted into a woman's uterus by a trained health care provider. Sub-dermal implants are progestin containing rods that are inserted under the skin and can prevent pregnancy for up to five years. Among all reversible modern contraceptives, IUDs are the most
Correspondence: Ephrem Geja School of Nursing, College of Medicine and Health Sciences Hawassa University, PO Box 05, Hawassa, Sidama Regional State, Ethiopia

Tel +25I-9l I-066-463

Email ephi.geja@gmail.com

Open Access Journal of Contraception 2021:12 35-44 
cost-effective and efficient methods in preventing pregnancy for up to 10 years. ${ }^{2,3}$ Implants are also long-acting and extremely effective at preventing pregnancy, with less than one percent of clinical failure rate. ${ }^{1}$

Of course, no single method is appropriate for all women. However, despite there being a wide range of contraceptive methods, which are freely available, there are still large numbers of unintended pregnancies ending with abortion every year. For several reasons, many women find it difficult to use contraception consistently and correctly. ${ }^{4}$

LARC methods are commonly discontinued when there is pregnancy while using when a woman has a desire to become pregnant, infrequent sex, husband live away, marital dissolution, or menopause or when a woman is not satisfied with the method or cannot access or afford it. ${ }^{5}$ In different countries, a significant number of women become exposed to the risk of conception after discontinuation. Consequently, the majority of unintended pregnancies ended with abortion or miscarriage. ${ }^{6}$

In Ethiopia, among all women using implants; $2 \%$ will discontinue before 6 months and about $11 \%$ before 1 year after insertion. Among the IUD users, $27 \%$ and $34 \%$ will remove the device within 1 and 3 years of insertion. ${ }^{7}$ The study done in three regional states of Ethiopia shows, $15.1 \%$ of the respondents had at least one abortion episode. ${ }^{8}$

The controversy between high discontinuation rate and high demand suggests unmet need due to method dissatisfaction. This might increase women's vulnerability to unintended pregnancies-if they do not start another method of contraception. There are inadequate and inconsistent reports indicating high numbers of implant and IUD early removals. This will promote concern among local service providers and highlight the need to review the removal rates and reasons for removal. ${ }^{7}$ Besides, LARC methods are known for their high effectiveness and comprise an increasing share of contraceptive use. Therefore, it is imperative to examine how often and why women discontinue these methods, particularly in low-income countries. $^{5}$ This study was conducted to determine implant and IUD early removal rates and its determinants in Sidama Regional State, Ethiopia.

\section{Methods and Materials}

\section{Study Design and Setting}

A community-based cross-sectional study was conducted in Sidama Regional State, Southern Ethiopia from June 1 to 30, 2019. Sidama Regional State is found in the Southern part of Ethiopia. The Region is divided into 36 districts and on average each district has a population of 100,000 . According to the Central Statistical Agency (CSA) population projection for 2016, the zone has a total population of $3,590,471$ of whom $1,810,134(50.48 \%)$ are men and 1,780,337 (49.52\%) women. According to the 2016 Southern Nations Nationalities and Peoples Regional State/ SNNPRS health bureau annual report, a total of 601,553 reproductive-age women were used modern family planning in Sidama Regional State. Of whom 92,519 (15.38\%) women used LARCs. This research aims to assess the prevalence of early removal rate of long-acting and reversible contraceptives and its associated factors in Sidama Regional State, Southern Ethiopia, from June 1 to 30, 2019.

\section{Population and Sampling}

All reproductive age group women who ever used implants or IUDs from the selected 21 kebeles (the smallest administrative unit in Ethiopia) of Sidama Regional State (period of June 1, 2014, up to May 30, 2017) were recruited as the source population of this study. The study population was selected from those women who used either of the above LARCs during the last three years preceding the data collection period. Women who started using LARCs within less than twelve months period preceding the study were excluded.

The required sample size was estimated assuming; $35.0 \%$ of women who removed LARCs methods early after insertion (9), 0.05 level of significance $(\alpha)$, and 5\% limits of error. Also, a design effect of 1.5 was used to minimize sampling error. Thus, the estimated sample size with the addition of a $10 \%$ non-response rate was 525 .

A multi-stage sampling technique was implemented. In the first stage, six districts and one city administration were selected by a simple random sampling technique using the lottery method. Then, 21 kebeles were selected similarly. Women who ever used LARCs in the selected kebeles were identified from family planning registration books of health facilities and family planning utilization documents at health posts. Finally, a systematic sampling technique was employed to select study participants from the identified list of women who ever used these methods. 


\section{Data Collection Procedure}

A structured and pre-tested interview-based questionnaire with both open and closed-ended questions was used to collect data. The questionnaire was developed after reviewing different literature and scientific facts. First, it was prepared in English and translated into Amharic. The Amharic version was retranslated back to English by another person to check whether the translation was consistent with the English version. The data collection tool contains questions about socioeconomic and demographic conditions, past contraception history and Knowledge on LARCs, partner involvement, counseling status, future intention, and information specifically about the use of LARCs. Seven data collectors and two supervisors have collected the data through the home to home visit. Local guides were used to identify the house of the selected women.

\section{Measurement}

Early removal of long-acting and reversible contraceptive: To be consistent with previously published data, early discontinuation was defined as the removal of the Implants or IUD within one year of its placement. ${ }^{10}$

\section{Data Processing and Analysis}

Data were entered into Epi Info version 3.4.3 and then exported to SPSS version 20 for analysis. Summary statistics were computed to determine frequencies and percentages. Bivariate analysis was conducted primarily to check the association of each independent variable with the dependent variable-early removal of LARCs. To control for the possible effect of confounding, variables found to have an association with the dependent variables at a P-value of 0.2 on the bivariate logistic regression analyses were entered into multivariate logistic regression analysis. Those variables which had significant association at p-value less than 0.05 in the multivariate logistic regression were considered to be independent predictors of early removal of LARCs. The final model was diagnosed by Hosmer and Lemeshow goodness of fit tests. Results were presented using tables, charts, and graphs.

\section{Data Quality Control}

To ensure the quality of data, the questionnaire was pre-tested on $5 \%$ of the total sample size out of the selected kebeles. Possible restructuring and adjustment of the questions were made after the pretest. Orientation was given for data collectors and supervisors. The data collection process was conducted with close supervision of the assigned supervisors, while completeness and accuracy of collected data were again reviewed and checked by the principal investigators.

\section{Ethical Consideration}

Ethical clearance was obtained from the Institution Review Board of Hawassa University, College of Medicine and Health Sciences. Permission and support letter was obtained from the SNNPRS Health Bureau and the Sidama Regional State Health Department. Then an official letter was written to each service delivery point. An information sheet that contains about the benefit and risk of participating in the respondents in this study with verbal informed consent was attached to each questionnaire to brief and obtained the consent of each study participant. Verbal informed consent obtained from the participants was approved by the Institution Review Board of Hawassa University. This study was also conducted in accordance with the Declaration of Helsinki.

\section{Result}

\section{Socio-Demographic Characteristics of Study Participants}

A total of 475 reproductive age group women were included in the study but 429 participants were participated and make the response rate of $90.4 \%$. The mean ( \pm Standard deviation (SD)) age of the respondents was 29.81 ( \pm 5.69$)$ years Urban residents account for 408 $(85.9 \%)$ of women. Nearly half 273 (49.9\%) were Protestant by religion followed by orthodox, 203 (43.7\%). Four hundred forty-three (93.3\%) of the LARCs users were married and 22 (4.6\%) were singles. Only 9 $(1.95 \%)$ of the respondents had no formal education while 443 (93.3\%) had formal education. Housewives account for $286(60.2 \%)$, followed by $124(26.2 \%)$ government employees. Thirty-seven $(7.8 \%)$ of the women were not able to estimate their monthly income and $105(22.1 \%)$ of them reported an estimated monthly income between 2000 and 3000 Ethiopian birrs (Table 1).

\section{Maternal and Reproductive Characteristics}

One fourth (25.3\%) had two children before using LARC methods. Currently, one among five 91 (19.2\%) women has more than four children. One hundred and twentyseven women $(26.7 \%)$ had no intention to have children 
Table I Socio-Demographic Characteristics of Women Who Received LRCMs in Sidama Regional State, Southern Ethiopia, 2019

\begin{tabular}{|c|c|c|c|}
\hline \multicolumn{2}{|l|}{ Characteristics } & \multirow{2}{*}{$\begin{array}{l}\text { Frequency } \\
55\end{array}$} & \multirow{2}{*}{$\begin{array}{l}\text { Percent } \\
11.6\end{array}$} \\
\hline Age group & $\leq 24$ & & \\
\hline & $25-29$ & 203 & 42.7 \\
\hline & $30-34$ & 112 & 23.6 \\
\hline & $35-39$ & 73 & 15.4 \\
\hline & $\geq 40$ & 32 & 6.7 \\
\hline \multirow[t]{2}{*}{ Residence } & Urban & 408 & 85.9 \\
\hline & Rural & 67 & 14.6 \\
\hline \multirow[t]{3}{*}{ Religion } & Protestant & 237 & 49.9 \\
\hline & Orthodox & 203 & 42.7 \\
\hline & Other & 35 & 7.3 \\
\hline \multirow[t]{3}{*}{ Marital status } & Single & 22 & 4.6 \\
\hline & Married & 443 & 93.3 \\
\hline & Others & 10 & 2.2 \\
\hline \multirow[t]{4}{*}{ Education } & No formal education & 32 & 6.7 \\
\hline & $<8$ years & 149 & 31.4 \\
\hline & $9-12$ years & 199 & 41.9 \\
\hline & $>12$ years & 95 & 20 \\
\hline \multirow[t]{5}{*}{ Occupation } & Student & 11 & 2.3 \\
\hline & Merchant & 41 & 8.6 \\
\hline & Government worker & 124 & 26.1 \\
\hline & House wife & 286 & 60.2 \\
\hline & Others & 13 & 2.7 \\
\hline \multirow[t]{7}{*}{ Monthly income } & Do not know & 37 & 7.8 \\
\hline & $\leq 1000$ birr & 32 & 6.7 \\
\hline & $100 \mid-2000$ birr & 89 & 18.7 \\
\hline & 200I-3000 birr & 105 & 22.1 \\
\hline & $300 \mathrm{I}-4000$ birr & 66 & 13.9 \\
\hline & $400 \mathrm{I}-5000$ birr & 65 & 13.7 \\
\hline & $>5000$ birr & 81 & 17.7 \\
\hline
\end{tabular}

in the future, whereas, $52(10.9 \%), 110(23.2 \%)$, and 100 (21.1\%) had an intention for one, two, and three children in the future, respectively. Women who had a history of at least one abortion were 79 (16.6\%) (Table 2).

\section{Family Planning Knowledge and Service}

Nearly all, 467 (98.3\%) of women have information about injectable contraceptives. Three hundred eighty-seven $(81.5 \%)$ of them have also responded that they know about oral contraceptive pills. Those participants who reported as having information about Implanon, jadelle, and IUD were 416 (68.8\%), 383 (80.6\%), and 306 (64.4\%)
Table 2 Maternal and Reproductive Characteristics of Women Who Received LRCMs in Sidama Regional State, Southern Ethiopia, 2019

\begin{tabular}{|l|l|l|}
\hline Characteristics & Frequency & Percent \\
\hline \multicolumn{2}{|l|}{ Children before utilization } \\
\hline No children & 31 & 6.5 \\
I child & 65 & 13.7 \\
2 children & 120 & 25.3 \\
3 children & 97 & 20.4 \\
4 children & 71 & 14.9 \\
$\geq 5$ children & 91 & 19.2 \\
\hline Current children & \multicolumn{2}{|l}{} \\
\hline No children & 26 & 5.5 \\
I child & 52 & 10.9 \\
2 children & 110 & 23.2 \\
3 children & 100 & 21.1 \\
$\geq 4$ children & 187 & 39.4 \\
\hline Intention to have more children & 16.6 \\
\hline No intention & 127 & 83.4 \\
\hline c child & 61 & 12.8 \\
2 children & 211 & 44.1 \\
$\geq 3$ children & 76 & 16 \\
\hline Abortion history & 79 & \\
\hline Yes & 396 & \\
No & \multicolumn{2}{|l}{} \\
\hline
\end{tabular}

respectively. Health professionals were the source of information for 412 (86.7\%) of women in this study. Duration of pregnancy protection was the most reported known type of information on both methods; intradermal (86.7\%) and IUD (82.5\%) (Table 3).

Of the total women in this study, 354 (74.5\%) received a family planning service for LARC from health centers. Four hundred twenty-three of them reach the health facilities within less than 30 minutes of walking. Almost all (99\%) women received counseling before the insertion of the method. The counseling duration was less than 15 minutes for $281(59.2 \%)$ of the clients. The family planning service was satisfying for $349(73.5 \%)$ of the users (Table 4).

Information about the advantage and duration of action of LARC methods were the most frequently addressed topics during counseling. Four hundred (84.2\%) of 
Table 3 Information on FPM Among Women Who Used LRCMs in Sidama Regional State, 2019

\begin{tabular}{|c|c|c|}
\hline Characteristics & Frequency & Percent \\
\hline \multicolumn{3}{|l|}{ Has information about } \\
\hline Pills & 387 & 81.5 \\
\hline Injectables & 467 & 98.3 \\
\hline Lactation amenorrhea & 61 & 12.8 \\
\hline Female condom & 40 & 8.4 \\
\hline Male condom & 327 & 68.8 \\
\hline Implanon & 416 & 87.6 \\
\hline Jadelle & 383 & 80.6 \\
\hline IUD & 306 & 64.4 \\
\hline Female Sterilization & 49 & 10.3 \\
\hline Male Sterilization & 29 & 6.1 \\
\hline \multicolumn{3}{|c|}{ Information about intradermal methods } \\
\hline Effectiveness & 375 & 78.9 \\
\hline Side effects & 63 & 13.3 \\
\hline Duration of pregnancy prevention & 412 & 86.7 \\
\hline Benefit & 263 & 55.4 \\
\hline \multicolumn{3}{|l|}{ Information about IUD } \\
\hline Effectiveness & 332 & 69.9 \\
\hline Side effects & 262 & 55.2 \\
\hline Duration of pregnancy prevention & 392 & 82.5 \\
\hline Benefit & 280 & 58.9 \\
\hline \multicolumn{3}{|l|}{ Source of information } \\
\hline Health professional & 412 & 86.7 \\
\hline HEW & 193 & 40.6 \\
\hline Friends or families & 108 & 22.7 \\
\hline Radio/ television & 197 & 41.5 \\
\hline News paper/ magazine & 36 & 7.6 \\
\hline Other printed materials & 2 & 0.4 \\
\hline
\end{tabular}

women were advised about the advantage of these methods and $373(78.5 \%)$ about its duration of action (Figure 1).

\section{Family Planning Methods Utilization and Early Removal}

There were 110 (23.2\%) women who ever used oral contraceptives and 374 (78.7\%) injectable methods. Implanon, Jadelle and IUD ever users were 207 (43.6), 191 (40.2\%), and $77(16.2 \%)$ respectively. From the total 398 intradermal (Implanon/Jadelle) contraceptive users, 320 (80.4\%) are still using the methods currently. Out of 77 IUD ever users in this study, 55 (71.4\%) are using currently (Figure 2).
Table 4 Family Planning Services Provided for LRCMs Users in Sidam Regional State, 2019

\begin{tabular}{|c|c|c|}
\hline Characteristics & Frequency & Percent \\
\hline \multicolumn{3}{|l|}{ Place of insertion } \\
\hline Health center & 354 & 74.5 \\
\hline Health post & 8 & 1.7 \\
\hline Hospital & 75 & 15.8 \\
\hline NGO health facility & 29 & 6.1 \\
\hline Private health facility & 9 & 1.9 \\
\hline \multicolumn{3}{|l|}{ Time to reach the source } \\
\hline$\leq 30$ minutes & 423 & 89.1 \\
\hline$>30$ minutes & 52 & 10.9 \\
\hline \multicolumn{3}{|c|}{ Get counseling before insertion } \\
\hline Yes & 471 & 99.2 \\
\hline No & 4 & 0.8 \\
\hline \multicolumn{3}{|l|}{ Type of counseling } \\
\hline Individual counseling & 364 & 76.6 \\
\hline Mass counseling & 81 & 17.1 \\
\hline With husband counseling & 30 & 6.3 \\
\hline \multicolumn{3}{|l|}{ Duration of counseling } \\
\hline$\leq 15$ minutes & 281 & 59.2 \\
\hline $15-30$ minutes & 189 & 39.8 \\
\hline$>30$ minutes & 5 & I.I \\
\hline \multicolumn{3}{|l|}{ Duration before insertion } \\
\hline$<30$ minutes & 343 & 72.2 \\
\hline 30 minutes- I day & 44 & 9.3 \\
\hline$>1$ day & 88 & 18.5 \\
\hline \multicolumn{3}{|l|}{ Service satisfaction } \\
\hline Satisfied & 349 & 73.5 \\
\hline Unsatisfied & 126 & 26.5 \\
\hline
\end{tabular}

Of the total participants in this study, 49 discontinued LARC methods within 12 months of use. Based on this, the overall early removal rate of LARCs was $10.3 \%(95 \%$ confidence interval: 7.57-13.06). The proportion of early removal was $10.8 \%$ among implant users and $7.8 \%$ among IUD users. Eleven (22.4\%) of the total early discontinuers used these methods for less than 6 months and the remaining $38(77.6 \%)$ used 6 to 12 months (Figure 3).

The three most common reasons for discontinuation of LARCs were; plan to conceive soon (28.8\%), fear of side effect $(27.4 \%)$, and health concerns together with bodyweight loss $(16.4 \%)$. Weight gain with health concerns was mentioned by $4.1 \%$ of women as a reason for the removal (Figure 4 ). 


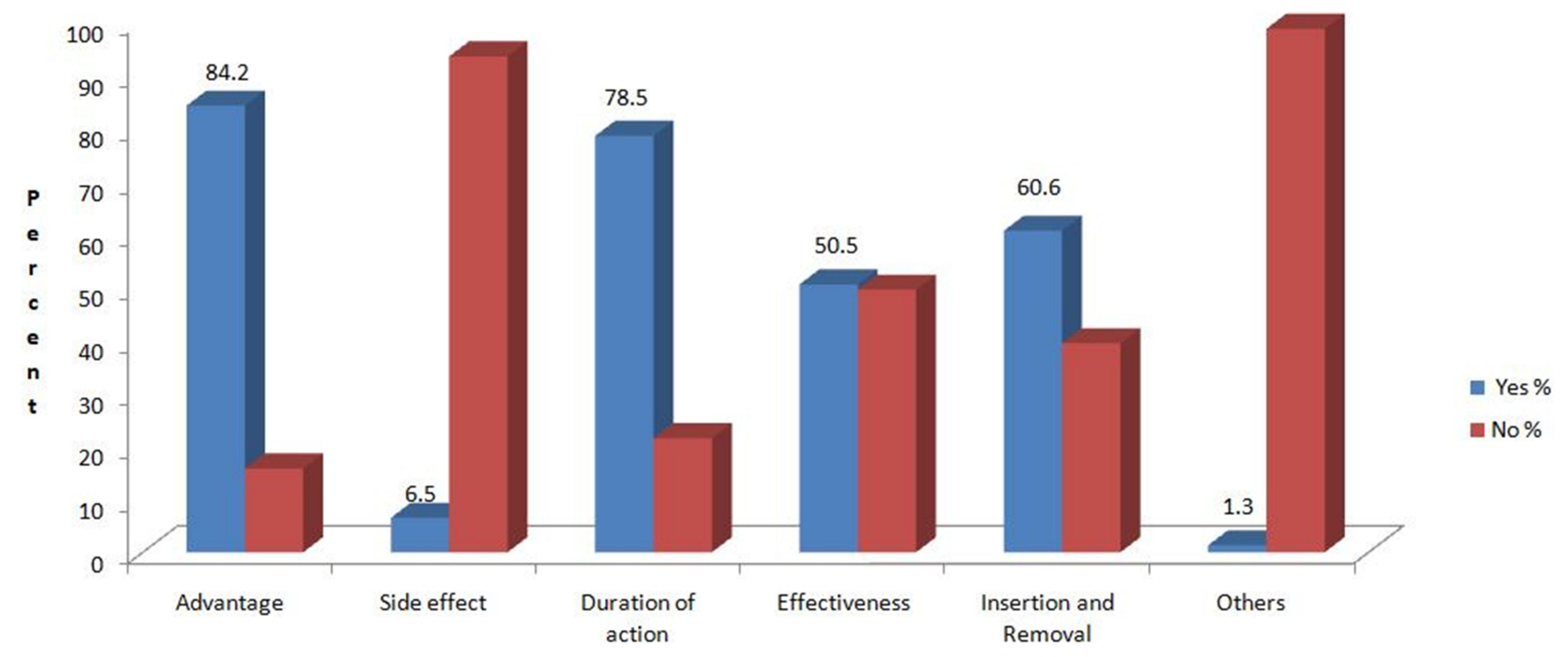

Figure I Distribution of counseling information given for LRCMs utilizers in Sidama Regional State, Ethiopia, 2019.
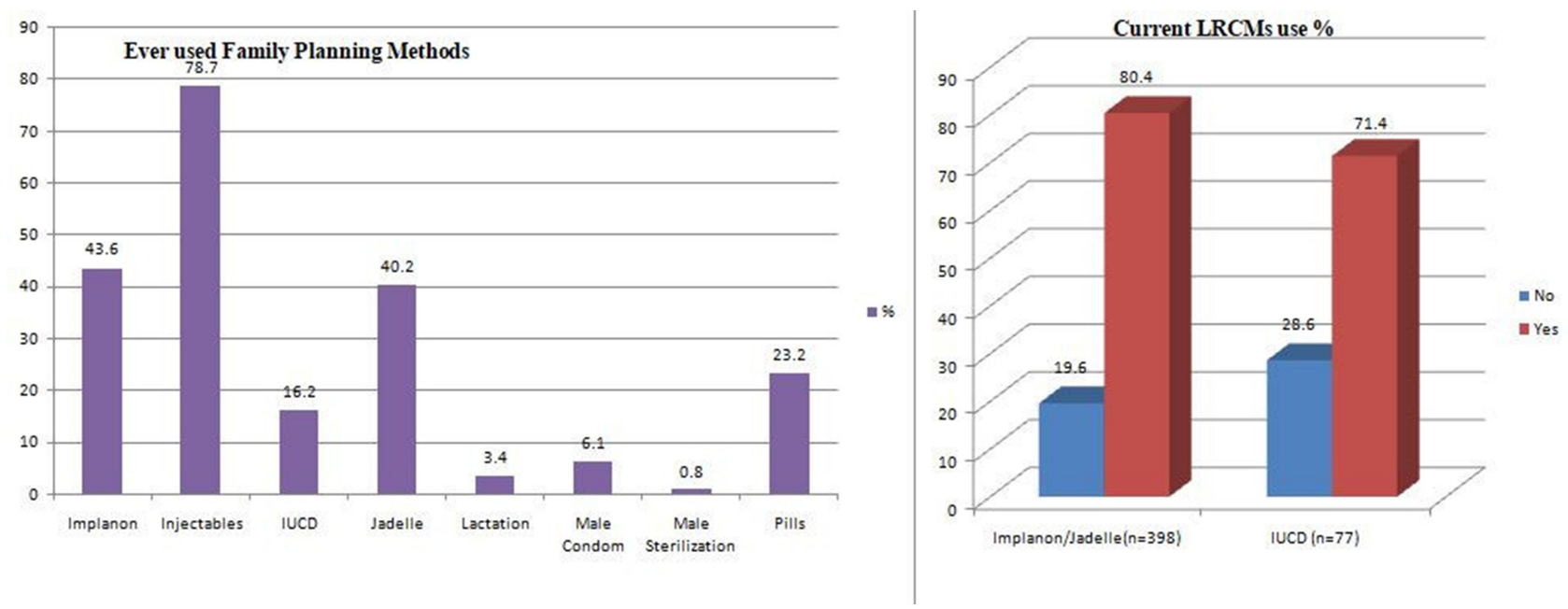

Figure 2 Distribution of ever used family planning methods and current LRCMs use among women who received LRCMs in Sidama Regional State, Southern Ethiopia, 2019.

Factors Associated with Early Removal of LRCMs

On the bivariate analysis, age, educational status, intention to have more children, service satisfaction, counseling about advantage, side effect, and effectiveness were selected as a candidate variable for multivariate analysis. On the final model; women's age, educational status, service satisfaction, counseling about advantage, and effectiveness were identified as independent predictors of LARC's early removal.

Women whose age is between 25 and 29 years [OR= 9.86 (95\% CI: 2.22-43.74)] and those between 30 and 34 years $[\mathrm{OR}=11.5(95 \% \mathrm{CI}: 2.67-49.56)]$ were about 10 and
11 times more likely to remove LARCs within one year period than women whose age is above 35 years. When compared to women with no formal education, those who spent $\leq 8$ years $[\mathrm{OR}=0.32(95 \% \mathrm{CI}: 0.11-0.93)], 9-12$ years $[\mathrm{OR}=0.19(95 \% \mathrm{CI}: 0.06-0.58)]$ and $>12$ years $[\mathrm{OR}=0.26$ (95\% CI: $0.26-0.98)]$ in school are $68 \%, 81 \%$ and $74 \%$ less chance of removing LRCMs before one year of use, respectively.

Women who are not advised about the advantage [OR= 2.81 (95\% CI: 1.23-6.40)] and effectiveness $[\mathrm{OR}=2.70$ (95\% CI: 1.30-5.60)] of LARCs had three times higher probability of discontinuing the method within 12 months of insertion than those who received pieces of advice on 

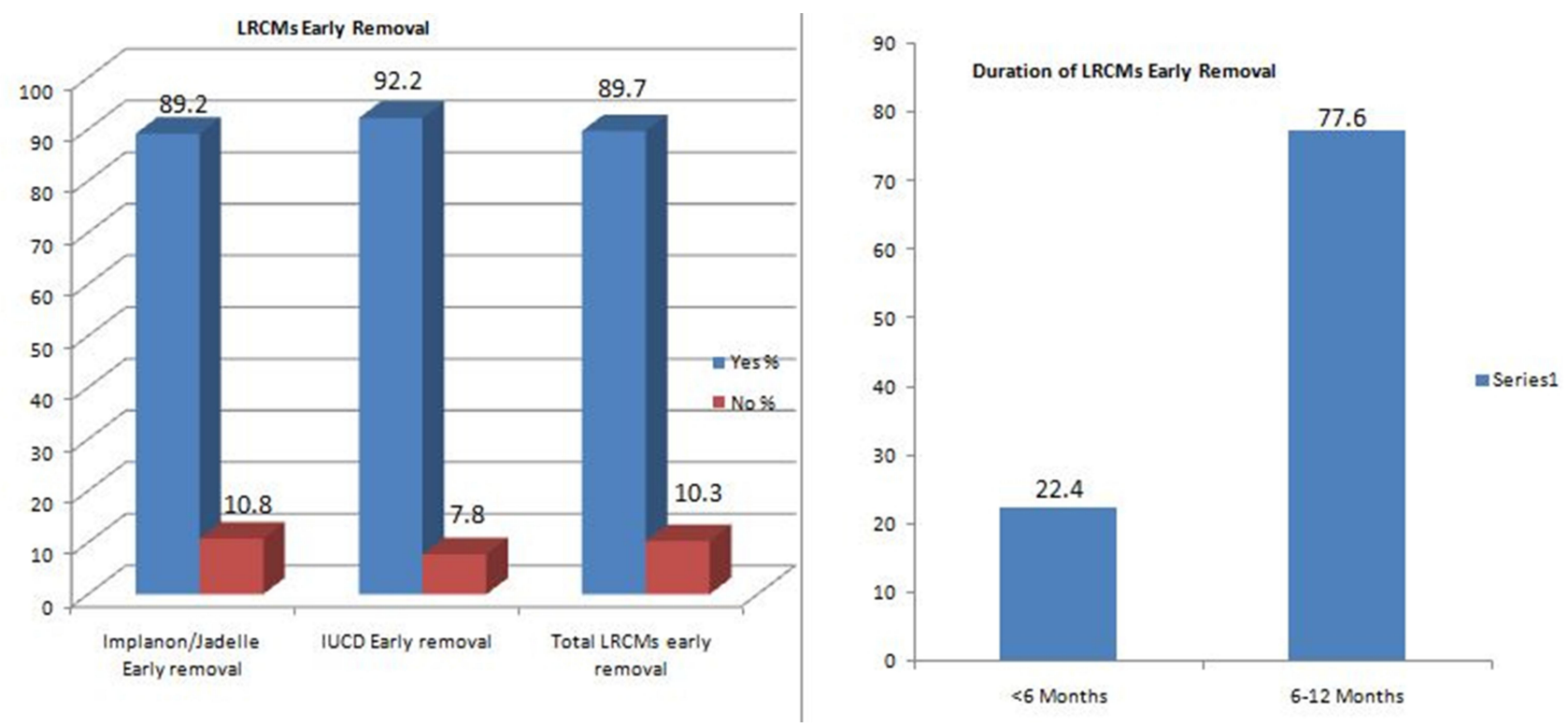

Figure 3 Distribution of early LRCMs removal and Duration for removal among women who received LRCMs in Sidama Regional State, Southern Ethiopia, 2019.

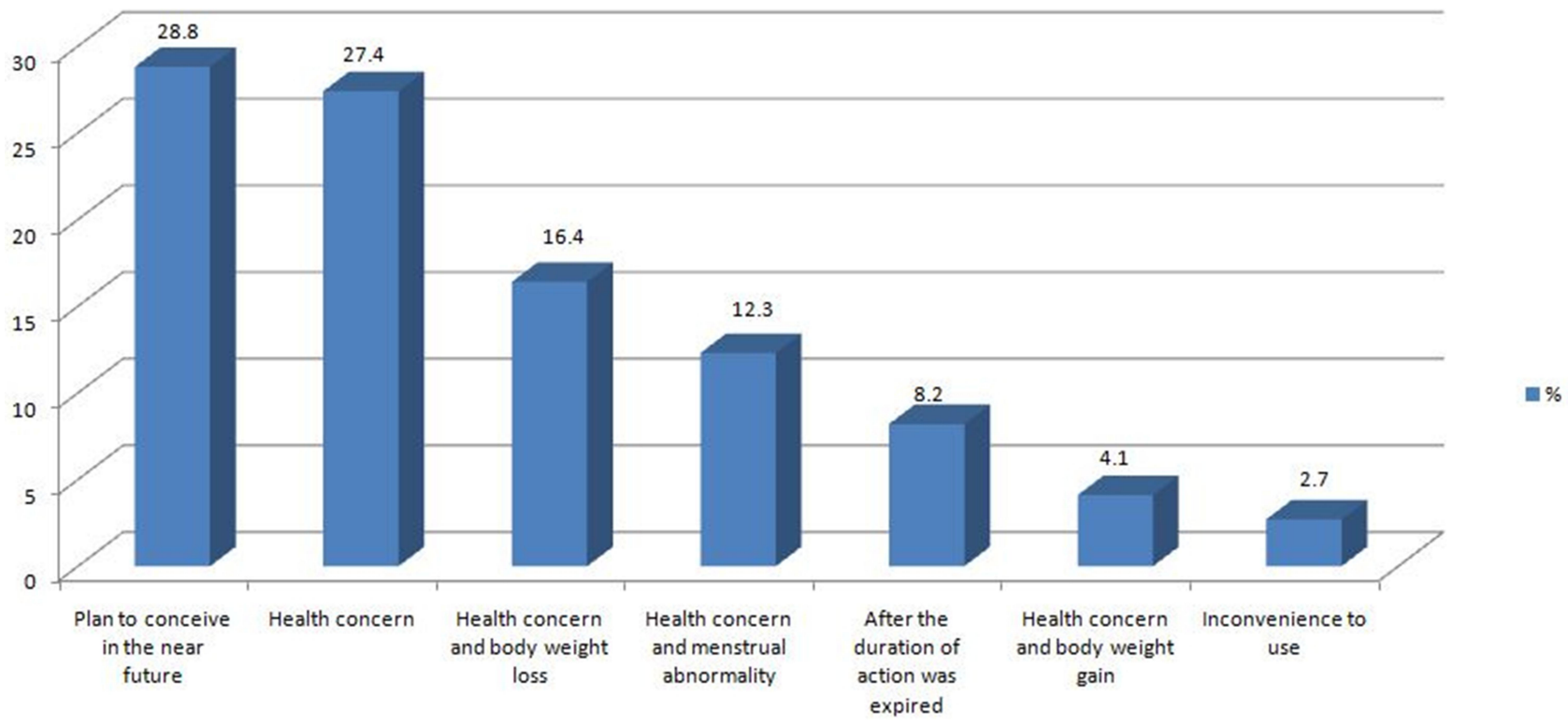

Reasons for early removal of LRCMs

Figure 4 Reasons for removal of LRCMs mentioned by women who removed the methods in Sidama Regional State, Southern Ethiopia, 2019.

advantage and effectiveness. Unsatisfied women with the family planning service had about two times greater risk of early LARCs removal than those who are satisfied $[\mathrm{OR}=$ 2.24 (95\% CI: 1.10-4.57)] (Table 5).

\section{Discussion}

In this study, early removal of LARC methods was defined as discontinuation of the methods within 12 months of use.
Based on this, the prevalence of LARCs early removal rate was $10.3 \%$. Out of these, $22.4 \%$ discontinued within 6 months of use and the remaining $77.6 \%$ discontinued within 6 to 12 months of use.

The prevalence of LARC methods early removal rate in this study was higher than the results of the study done in Agarfa District, Bale Zone, South East Ethiopia that reported implants had a discontinuation rate of just $4.0 \%{ }^{11}$ 
Table 5 Factors Associated with Early Removal of LRCMs Among Women Who Used These Methods in Sidam Regional State, 2019

\begin{tabular}{|c|c|c|c|c|}
\hline \multirow[t]{3}{*}{ Variables $(n=475)$} & \multicolumn{2}{|c|}{ LRCM Early Removal } & \multirow[t]{3}{*}{ COR $(95 \% \mathrm{Cl})$} & \multirow[t]{3}{*}{ AOR $(95 \% \mathrm{Cl})$} \\
\hline & Yes & No & & \\
\hline & No(\%) & No(\%) & & \\
\hline \multicolumn{5}{|l|}{ Age group } \\
\hline$\leq 24$ & $3(5.5)$ & $52(94.5)$ & $1.96(0.38-10.05)$ & $2.37(0.37-14.93)$ \\
\hline $25-29$ & $26(12.8)$ & $177(87.2)$ & $4.99(|.47-| 6.91)^{*}$ & $9.86(2.22-43.74)^{* *}$ \\
\hline $30-34$ & $17(15.2)$ & $95(84.8)$ & $6.08(|.72-2| .42)^{*}$ & II $.5(2.67-49.56)^{* *}$ \\
\hline$\geq 35$ & $3(2.9)$ & $102(97.1)$ & I & I \\
\hline \multicolumn{5}{|l|}{ Educational status } \\
\hline No formal education & $9(28.1)$ & 23 (7I.9) & $\mathrm{I}$ & I \\
\hline$\leq 8$ years & $18(12.1)$ & $|3|(87.9)$ & $0.35(0.14-0.87)^{*}$ & $0.32(0.11-0.93)^{* *}$ \\
\hline $9-12$ years & $16(8.0)$ & $183(92.0)$ & $0.22(0.08-0.56)^{*}$ & $0.19(0.06-0.58)^{* *}$ \\
\hline$>12$ years & $6(6.3)$ & $89(93.7)$ & $0.17(0.05-0.533)^{*}$ & $0.26(0.06-0.98)^{* *}$ \\
\hline \multicolumn{5}{|c|}{ Intention for more children } \\
\hline No intention & $9(7.1)$ & $118(92.9)$ & $0.40(0.16-1.07)$ & $0.51(0.15-1.70)$ \\
\hline I-2 children & $28(10.3)$ & $244(89.7)$ & $0.61(0.29-1.27)$ & $0.52(0.21-1.27)$ \\
\hline$\geq 3$ children & $12(15.8)$ & $64(84.2)$ & 1 & 1 \\
\hline \multicolumn{5}{|c|}{ Counseled about advantage } \\
\hline Yes & $31(7.8)$ & $369(92.2)$ & 1 & 1 \\
\hline No & $18(24.0)$ & $57(76.0)$ & $3.75(1.97-7.16)^{*}$ & $2.8 \mathrm{I}(1.23-6.40)^{* *}$ \\
\hline \multicolumn{5}{|c|}{ Counseled about side effects } \\
\hline Yes & $6(19.4)$ & $25(80.6)$ & $2.23(0.87-5.75)$ & $2.08(0.57-7.58)$ \\
\hline No & $43(9.7)$ & $40 \mathrm{I}(90.3)$ & 1 & 1 \\
\hline \multicolumn{5}{|c|}{ Counseled about effectiveness } \\
\hline Yes & $14(5.8)$ & $226(94.2)$ & I & 1 \\
\hline No & $35(14.9)$ & $200(85.1)$ & $2.82(1.47-5.40)^{*}$ & $2.70(1.30-5.60)^{* *}$ \\
\hline \multicolumn{5}{|l|}{ Service satisfaction } \\
\hline Satisfied & $26(7.4)$ & $323(92.3)$ & I & I \\
\hline Unsatisfied & $23(18.3)$ & $103(82.4)$ & $2.77(\mathrm{I} .5 \mathrm{I}-5.07)^{*}$ & $2.24(1.10-4.57)^{* *}$ \\
\hline
\end{tabular}

Note: *P-value $<0.05$ on COR, **P-value $<0.05$ on AOR.

This difference might be due to the difference in the age of participants, science, the majority of women in the current study were young, and being young can be associated with a high desire of having more children which in turn leads to a high discontinuation rate. The other possible reason might be inadequate pre-insertion counseling particularly about the advantage and effectiveness of the method.

In contrast, the early LARC removal rate was lower than the contraceptive discontinuation in developing countries in the first year of use; which is $18-63 \% .{ }^{12}$ It was also lower than the results of studies conducted in Nigeria,
Egypt, Malaysia, and a multi-centered study in other nine countries, which indicated the overall Implanon discontinuation rates of $26.1 \%, 28.0 \%, 22.86 \%$, and $20.0 \%$, respectively. ${ }^{13-16}$ The rate was also lower than a $35 \%$ national early discontinuation in Ethiopia. ${ }^{9}$ Besides, in the study conducted in Debre Markos, Ethiopia, the rates of discontinuation at 6 months, 12 months, and 24 months were $10.5 \%, 23.9 \%$, and $38.2 \%$, respectively. ${ }^{17}$ These discrepancies could be due to the difference in the composition of study participants as most of these studies are conducted by focusing on the rural population. 
Also, the expansion of the health extension program in our study area and the country from time to time might be the reason for the observed difference.

The satisfaction of women with family planning service and improved counseling has a positive impact on the early removal of LARC in our study. This finding was in line with results from the study at the Medical University of South Carolina. ${ }^{18}$

In our study, age group, educational status, service satisfaction, counseling about advantage, and effectiveness were identified as independent predictors of early removal of LRCMs. Similarly, the study conducted in Debre Markos Ethiopia showed that attending college and above level education, absence of pre-insertion counseling service, and perceived level of unsatisfying family planning service were significantly associated with Implanon discontinuation. ${ }^{17}$

The most common reasons mentioned for early removal by the current study participants were the desire for pregnancy and fear of side effects. This was in line with previous studies, which showed a plan to conceive soon, and the view of side effects was the most frequently given reason. ${ }^{19-21}$

Despite its strengths, the study has some limitations. Qualitative methods were not included in the study which would support the quantitative results. Besides, some of the women who ever used LARCs outside of the catchment area and whose information about their utilization is inaccessible from health extension workers were not included.

\section{Conclusions and Recommendations}

The early removal rate of LARC is in considerable magnitude among women who ever used these methods in Sidama Regional State. The main predictors for early discontinuation of these methods were family planning service-related factors. These include; perceived satisfaction of clients by the family planning service, provision of proper counseling about the advantage, and effectiveness of the methods. Also, socio-demographic factors like; age less than 35 years and educational status are among the significant predictors for early discontinuation of these methods.

Therefore, measures targeted to improve the satisfaction of clients with family planning services and proper counseling on the advantages and effectiveness of these methods should be considered to get LARCs early removal rate lower.

\section{Abbreviations}

CSA, Central Statics Agency; FGA, Family Guidance Association; FP, family planning; HEW, health extension worker; IUDs, intrauterine devices; LARC, long-acting reversible contraceptive; $\mathrm{MCH}$, maternal and child health; REC, Research and Ethical Committee; SRS, Sidama Regional State; SPSS, Statistical Package for Social Science.

\section{Data Sharing Statement}

Data supporting the findings of this study are presented in the manuscript.

\section{Ethics Approval and Consent to Participate}

Ethical clearance was obtained from the Ethical review committee of the Hawassa University College of Medicine and Health Science \& permission was obtained from each participant.

\section{Acknowledgments}

We would like to express our gratitude to the study participants for their willingness in providing the necessary information. We would like to acknowledge health Extension workers of the selected kebeles for easing the data collection process. Our gratitude also goes to EzedineMolla, Seife Kibru, AmezenechAyele, Mohammed Ayalew, Fikru Tadesse, BediluDeribe, Sihne Tadesse, Kurabachew Mengistu, Tadesse Yohannes, Sileshi Demelash\&Abraham Abate for their unreserved support though out the paper preparation.

\section{Author Contributions}

All authors made a significant contribution to the work reported, whether that is in the conception, study design, execution, acquisition of data, analysis, and interpretation, or in all these areas; took part in drafting, revising, or critically reviewing the article; gave final approval of the version to be published; have agreed on the journal to which the article has been submitted; and agree to be accountable for all aspects of the work.

\section{Funding}

There is no funding to report.

\section{Disclosure}

All authors declare that they have no conflicts of interest for this work. 


\section{References}

1. Ramchandran D, Upadhyay UD. Implants: The Next Generation. Population Reports. Baltimore, INFO Project, Johns Hopkins Bloomberg School of Public Health. October 2007. Available from: http://www.populationreports.org/k7/. Accessed January 28, 2021.

2. Ali M, Sadler R, Cleland J, Ngo T, Shah I. Long-Term Contraceptive Protection Discontinuation and Switching Behaviour. Intrauterine Device (IUD) Use Dynamics in 14 Developing Countries. London: World Health Organization and Marie Stopes International; 2011.

3. Hatcher R, Trussell J, Nelson A. Contraceptive Technology. New York, NY: Ardent Media; 2007.

4. Astbury Ward E. Provision of contraception and its influence on abortion. Nurs Pract. 2009;2009:47.

5. Staveteig S, Mallick L, Winter R. Uptake and Discontinuation of Long-Acting Reversible Contraceptives (Larcs) in Low-Income Countries. DHS Analytical Studies No. 54. Rockville, Maryland, USA. 2015. Available from: https://www.dhsprogram.com/publica tions/publication-as54-analytical-studies.cfm. Accessed January 28, 2021.

6. Frost JJ, Singh S, Finer LB. U.S. women's one-year contraceptive use patterns,2004. Perspect Sex Reprod Health. 2007;38-55.

7. Kidane A, Asefa T, Asres T, et al. Assessment of Implant and IUCD Removal in Ethiopia International Conference on Family Planning Research and Best Practices Kampala, Uganda November 2009. Family Health International. 2009.

8. Melkamu Y, Betre M, Tesfaye S. Utilization of post-abortion care services in three regional states of Ethiopia. Ethiop J Health Dev. 2010;2010(24 Special Issues 1):123-129.

9. Central Statistical Agency (CSA) [Ethiopia] and ICF. Ethiopia Demographic and Health Survey 2016. 2016.

10. Robinson, Register, Ebner, and Orr, Reducing Early Discontinuation Rates of Subdermal Contraception in Your Clinical Practice. In: Osteopathic Family Physician. Vol. 1. Addis Ababa, Ethiopia, and Rockville, Maryland, USA:CSA and ICF;2015:24-28

11. Bekele T, Gebremariam A, Tura P. Factors associated with contraceptive discontinuation in Agarfa District, Bale Zone, Southeast Ethiopia. Epidemiology (Sunnyvale). 2015;5(2):179. doi:10.4172/ 2161-1165.1000189
12. Bradley S, Schwandt HM, Khan S. Levels Trends and Reasons for Contraceptive Discontinuation. Calverton, Maryland, USA: ICF Macro. 2008.

13. Balogun O, Olaomo N, Adeniran A, Fawole A. Implanon sub-dermal implant: an emerging method of contraception in Ilorin, Nigeria. $J$ Med Biomed Sci. 2014;3(1):1-5. doi:10.4314/jmbs.v3i1.1

14. Mastor A, Khaing SL, Omar SZ. Users' perspectives on Implanon in Malaysia, a multicultural Asian country. Open Access $J$ Contracept. 2011;Volume 2:79-84. doi:10.2147/OAJC.S9674

15. Said MA-RM, Cairo U. Implanon Use Pattern Among Ministry of Health and Population Clients 2008-2012. Cairo: Faculty of Medicine; 2012.

16. Peipert Jeffrey F, Zhao Q, Allsworth JE, et al. Continuation and satisfaction of reversible contraception. Obstet Gynecol. 2011;117 (5):1105-1113. doi:10.1097/AOG.0b013e31821188ad

17. Siyoum M, Mulaw Z, Abuhay M, Kebebe H Implanon discontinuation rate and associated factors among women who ever used implanon in the last three years in Debre Markos Town, Northwest Ethiopia, 2016, cross sectional study. ARC $J$ Public Health Community Med. 2017;2(1):8-16.

18. Lori M, Vanessa A, Jessica J, et al. Satisfaction, early removal, and side effects associated with long-acting reversible contraception. Fam Med. 2013;45(10):701-707.

19. Obijuru L, Bumpus S, Auinger P, et al. Etonogestrel implants in adolescents: experience, satisfaction, and continuation. J Adolesc Health. 2016;58(3):284. doi:10.1016/j.jadohealth.2015.10.254

20. Harel Z, Frank M, Kollar L, et al. Adolescents' reasons for and experience after discontinuation of the long-acting contraceptives Depo-Provera and Norplant. J Adolesc Health. 1996;19(2):118. doi:10.1016/1054-139X(95)00322-J

21. Lara-Torre E, Spotswood L, Correia N, et al. Intrauterine contraception in adolescents and young women: a descriptive study of use, side effects, and compliance. J Pediatr Adolesc Gynecol. 2011;24:39.
Open Access Journal of Contraception

\section{Publish your work in this journal}

Open Access Journal of Contraception is an international, peerreviewed, open access, online journal, publishing original research, reports, reviews and commentaries on all areas of contraception. In addition to clinical research, demographics and health-related aspects, the journal welcomes new findings in animal and preclinical

\section{Dovepress}

studies relating to understanding the biological mechanisms and practical development of new contraceptive agents. The manuscript management system is completely online and includes a very quick and fair peer-review system. Visit http://www.dovepress.com/testimonials. php to read real quotes from published authors. 